\title{
Treatment options for wastewater effluents from pharmaceutical companies
}

\author{
${ }^{1}$ A. M. Deegan; ${ }^{1}$ B. Shaik; ${ }^{2}$ K. Nolan; ${ }^{1}$ K. Urell; ${ }^{3}$ M. Oelgemöller; ${ }^{1}$ J. Tobin; ${ }^{4 * A}$. Morrissey \\ ${ }^{1}$ School of Biotechnology, Dublin City University, Dublin, Ireland \\ ${ }^{2}$ School of Chemical Sciences, Dublin City University, Dublin, Ireland \\ ${ }^{3}$ School of Pharmacy and Molecular Sciences, James Cook University, Townsville, QLD 4811, Australia \\ ${ }^{4}$ Oscail, Dublin City University, Dublin Ireland
}

Received 13 December 2010; $\quad$ revised 24 January 2011; accepted 27 April 2011; $\quad$ available online 1 June 2011

\begin{abstract}
In recent years, concerns about the occurrence and fate of active pharmaceutical ingredients, solvents, intermediates and raw materials that could be present in water and wastewater including pharmaceutical industry wastewater has gained increasing attention. Traditional wastewater treatment methods, such as activated sludge, are not sufficient for the complete removal of active pharmaceutical ingredients and other wastewater constituents from these waters. As a result, complementary treatment methods such as membrane filtration, reverse osmosis and activated carbon are often used in conjunction with the traditional methods for treatment of industrial wastewater. Most of the literature published to date has been on the treatment of municipal wastewater. However, there is a growing body of research that looks at the presence of active pharmaceutical ingredients in industrial wastewater, the treatment of these wastewaters and the removal rates. This article, reviews these treatment methods and includes both traditional methods and advanced oxidation processes. The paper concludes by showing that the problem of pharmaceuticals in wastewaters cannot be solved merely by adopting end of pipe measures. At source measures, such as replacement of critical chemicals, reduction in raw material consumption should continue to be pursued as the top priority.
\end{abstract}

Keywords: Advanced oxidation; Industrial wastewater; Pharmaticeutical effluent; Personal care products

\section{INTRODUCTION}

The presence of Pharmaceuticals and personal care products (PPCPs) was first identified in surface and wastewaters in the United States and Europe in 1960s (Stumm-Zollinger and Fair, 1965). Concerns about their potential risk was raised in 1999 (Daughton and Ternes, 1999) with the issue attracting considerable interest after the presence of pharmaceuticals in river water was linked to feminisation of fish living downstream of Wastewater treatment plant (WWTP) outfalls (Larsson et al., 1999). Furthermore, a link between a non-steroidal anti-inflammatory drug, diclofenac and the renal failure of vultures contributing to the $>95 \%$ decline in its population in the Indian subcontinent since the 1990's has been reported

《*Corresponding Author Email: anne.morrissey@dcu.ie Tel.: +3531700 5480/ Fax: +35317005494
(Oaks et al., 2004). Public awareness were raised after a study showed that organic wastewater contaminants, including PPCPs, were present in $80 \%$ of 139 U.S. streams (Kolpin et al., 2002). Although the concentration levels of PPCPs found in the environment are at trace concentrations, their chemical persistence, microbial resistance and synergistic effects are still unknown (Ankley et al., 2007; Madukasi et al., 2010), which is a cause for concern. Moreover, low concentrations can elicit adverse effects on aquatic life (Miege et al., 2008; 2009).

Pharmaceuticals enter the environment from a myriad of scattered points. The main sources of contamination include pharmaceutical production plants, WWTPs, hospitals, landfills and even graveyards (Khetan and Collins, 2007; Lillenberg et al., 
2010). The most investigated route of entry of pharmaceuticals into the environment is that from municipal WWTPs. Human excretion of unchanged or slightly transformed Active pharmaceutical ingredients (APIs) conjugated to polar molecules such as glucoronide enters the WWTP where these conjugates may then be cleaved, releasing the original API into the environment (Heberer, 2002). Activated sludge WWTPs have received particular attention (Jones et al., 2007; Watkinson et al., 2007). A limited number of studies also found pharmaceuticals in drinking water (Webb et al., 2003) and hospital wastewater (Suarez et al., 2009). Monitoring of APIs being released from pharmaceutical production facilities is not routine and the importance of such releases has not yet been established (Larsson and Fick, 2009). Furthermore, pharmaceutical industry wastewaters may contain organic solvents, catalysts, additants, reactants, intermediates, raw materials and APIs (Sreekanth et al., 2009), which makes them difficult to treat. The presence of toxic or recalcitrant substances in such wastewater results in lower Chemical oxygen demand (COD) removal efficiencies (Chelliapan et al., 2006). It has been estimated that up to half of the pharmaceutical wastewater produced worldwide is released without any treatment (Enick and Moore, 2007). While some attention has been focused on Endocrine disrupting chemicals (EDCs) the removal of other specific APIs is largely ignored. Biological treatment of wastewater is the most common and economical wastewater treatment method (Kulik et al., 2008). However, biological methods have shown to be insufficient for the removal of all potentially hazardous constituents of the wastewater (Clara et al., 2005; Joss et al., 2005; Suman Raj and Anjaneyulu, 2005; Giri et al, 2008; 2010). Recently, Membrane bioreactor (MBR) technology, ozonation and advanced oxidation processes (AOPs) have shown varying degrees of efficiency for the treatment of pharmaceutical wastewaters (Andreozzi et al., 2005; Doll and Frimmel, 2005a, Perez-Estrada et al., 2005a; Andreozzi et al., 2006; Helmig et al., 2007). As the awareness of the inefficiencies of the individual treatment technologies for the removal of hazardous substances in pharmaceutical wastewater is increasing, the integration and combination of treatment technologies may provide a more effective, albeit expensive solution in the future. This review aims to provide an overview of the current knowledge regarding the range of treatment methods available for PPCP removal from industrial wastewaters in order to get baseline knowledge of the effectiveness of the various treatment options. This knowledge could help pharmaceutical production facilities to be prepared to take preventative measures before required to do so by legislation. This literature review was carried out at Dublin City University in 2010.

\section{Conventional treatment methods}

Biological treatment methods have traditionally been used for the management of pharmaceutical wastewater (Suman Raj and Anjaneyulu, 2005). They may be subdivided into aerobic and anaerobic processes. Aerobic applications include activated sludge, membrane batch reactors and sequence batch reactors (LaPara et al., 2002; Suman Raj and Anjaneyulu, 2005; Noble, 2006; Chang et al., 2008 and Chen et al., 2008). Anaerobic methods include anaerobic sludge reactors, anaerobic film reactors and anaerobic filters (Gangagni et al., 2005; Enright et al., 2005; Chelliapan et al., 2006; Oktem et al., 2007; Sreekanth et al., 2009). The wastewater characteristics play a key role in the selection of biological treatments. Solvents, APIs, intermediates and raw materials represent biologically recalcitrant substances which affect the efficiency of biological treatment systems (Oz et al., 2004; Helmig et al., 2007). Activated sludge (AS) treatment is unsuitable for the treatment of wastewater where the COD levels are greater than $4000 \mathrm{mg} / \mathrm{L}$ (Suman Raj and Anjaneyulu, 2005).

Conventional activated sludge with a long hydraulic retention time (HRT) has historically been the method of choice for the treatment of pharmaceutical industry wastewater (El Gohary and Abou-Elea, 1995; Oz et al., 2004). It has a lower capital cost than more advanced treatment methods and a limited operational requirement; it is generally more environmentally friendly than chlorination. However, high energy consumption, the production of large amounts of sludge (Sreekanth et al., 2009) and operational problems including colour, foaming and bulking in secondary clarifiers are associated with activated sludge plants (Oz et al., 2004). Factors which affect the efficiency of activated sludge facilities for the treatment of pharmaceutical wastewater include HRT, temperature, $\mathrm{pH}$, dissolved oxygen (DO), organic load, microbial community, presence of toxic or recalcitrant substances and the 
batch operation of pharmaceutical production facilities (LaPara et al., 2001a; LaPara et al., 2002; Suman Raj and Anjaneyulu, 2005). These variables require modification for adaptation to pharmaceutical industry wastewater.

Temperature is a key factor in the efficiency of activated sludge facilities. It has an important role in selecting individual microbial species and overall microbial diversity in the activated sludge. This is where industrial wastewater can be very different from municipal wastewater. COD removal and examination of 16s rRNA of the bacterial community in aerobic biological systems at $5{ }^{\circ} \mathrm{C}$ intervals between 30 and $70^{\circ} \mathrm{C}$ showed that high temperatures were limiting factors to COD removal (LaPara et al., 2001b). The number of bacterial species decline with temperature between $30-60^{\circ} \mathrm{C}$, with the activated sludge process failing at temperatures above $60-65^{\circ} \mathrm{C}$ (LaPara et al., 2001a). A two stage operation at $55^{\circ} \mathrm{C}$ followed by 30 ${ }^{\circ} \mathrm{C}$ produced a lower quality effluent than operation at $30^{\circ} \mathrm{C}$ alone. Therefore, water from high temperature processes must be cooled prior to treatment by AS, which increases the time and cost of treatment.

The impact of pharmaceuticals on the AS process appears to be negligible under normal operating conditions (Stamatelatou et al., 2003). However at higher concentrations, which may be expected in the wastewater of pharmaceutical manufacturing facilities, they may become inhibitory. While there are a number of limited studies on the removal efficiency of APIs from pharmaceutical manufacturing facilities, it is known that removal efficiency of municipal facilities is dependent on the APIs present in the wastewater (Urase et al., 2005). AS is an efficient method for the removal of some APIs, but not all from municipal facilities (Zwiener and Frimmel, 2003; Castiglioni et al., 2006; Watkinson et al., 2007). $\beta$-Lactam and quinlone drugs in particular appear to be susceptible to aerobic oxidation. In a WWTP in Brisbane Australia, $\beta$-Lactam antibiotics showed high biodegradability due to hydrolic cleavage of the $\beta$-lactam ring. Lincomycin and sulphonamides were the least affected by AS treatment (Joss et al., 2005). Similar studies have also found that the efficiency of the process is dependent on the compound under investigation (Joss et al., 2005). Ibuprofen, naproxen, bezafibrate and estrogens (estrone, estradiol and ethinylestradiol) showed a high degree of removal while sulfamethoxazole, carbamezapine and diclofenac showed limited removal (Clara et al., 2005; Joss et al., 2005; Xu et al., 2008). Removal efficiencies are likely to decrease due to the development of more resistant APIs (Khetan and Collins, 2007). A number of pilot scale studies were conducted using Sequence batch reactors (SBRs) and Membrane bioreactors (MBRs) in an attempt to improve the effectiveness of AS treatment (Clara et al. 2005; Radjenovic et al. 2007). SBR is an activated sludge method of treatment in which separate tanks for aeration and sedimentation are not required and there is no sludge return. This type of process is ideal for use in small systems or when land is limited (Ileri et al., 2003). In one study, removal rates of $82 \%$ Biochemical oxygen demand (BOD), $88 \%$ COD, $96 \% \mathrm{NH}_{3}$ and $98 \%$ Suspended solids (SS) from domestic and pharmaceutical wastewater were achieved with a SBR operated for a 4 $\mathrm{h}$ aeration and a 60 min sedimentation period (Ileri et al., 2003). In another study, slightly lower removal efficiencies at between 63-69 \% of COD levels were achieved using SBR technology (Aguado et al., 2008).

MBRs are known to be effective for the removal of bulk organics and can replace traditional methods or operate in combination with conventional AS systems or as hybrid systems (Noble, 2006). The main advantages of MBRs over AS is that they require less space for operation (Yang et al., 2006), and can also treat variable wastewater compositions (Chang et al., 2008). High COD and BOD removal have been demonstrated in pharmaceutical production facilities (De Wever et al., 2007). For example, a $10 \mathrm{~m}^{3}$ per day capacity MBR operated at a pharmaceutical facility in Taiwan, removed $95 \%$ of COD and $99 \%$ of BOD (Chang et al., 2008). However, complete removal of all APIs is rare (Helmig et al., 2007). While the MBR removed 17$\alpha$-estradiol, 17- $\beta$-estradiol, 17- $\alpha$-dihydroequilin, trimegestone, estriol, medrogestone, norgestrel, and estradiol valerate to near and below the detection limits, estrone, ethinyl estradiol, and venlafaxine, a selective serotonin reuptake inhibitor (SSRI), were shown to be more resistant to the MBR treatment (Helmig et al., 2007). One explanation for this is that pharmaceutical compounds are generally smaller than the membrane pores and so only substances sorbed on particles are retained (Radjenovic et al., 2007). In order to remove the smaller compounds, membranes such as those used in reverse osmosis or nanofiltration are used, however these are expensive, which has limited their widespread use (Clara et al., 2005). 
The advantages of anaerobic treatment over aerobic processes is its ability to deal with high strength wastewater, with lower energy inputs, sludge yield, nutrient requirements, operating cost, space requirement and improved biogas recovery. However, because a wide range of natural and xenobiotic organic chemicals in pharmaceutical wastewaters are recalcitrant and nonbiodegradable to the microbial mass within the conventional treatment system, anaerobic processes are not always effective in removing these substances.

One way around this is to use anaerobic microorganisms such as methanogenic archaea, which can adapt to levels many times those that inhibit unadapted methanogens (Fountoulakis et al., 2008) as well as incorporating different configurations including biomembrane reactors, stirred tank reactors, up-flow anaerobic filters and fluidised bed reactors (Gangagni Rao et al., 2005; Chelliapan et al., 2006; Oktem et al., 2007). Up-flow anaerobic stage reactors (UASRs) used as a pre-treatment to activated sludge for industrial effluent have been shown to be efficient for the removal of pharmaceuticals even at high concentrations (Chelliapan et al., 2006; Oktem et al., 2007). AUASR fed with real pharmaceutical wastewater containing the antibiotics tylosin and avilamycin showed a high degree ofCOD and drug removal (Chelliapan et al., 2006). For a Hydraulic retention time (HRT) of $4 \mathrm{~d}$, Organic loading rate (OLR) of $1.86 \mathrm{~kg} \mathrm{COD} \mathrm{m}^{-3} / \mathrm{d}$, COD reduction was 70 $75 \%$, with an average of $95 \%$ tylosin reduction; however, COD removal decreased with an increase in tylosin (Chelliapan et al., 2006). A hybrid Up-flow anaerobic sludge blanket reactor (USABR) which combines a UASR and anaerobic filter technology showed significant removal of COD at a much higher OLR from pharmaceutical wastewater (Oktem et al., 2007). For a HRT of 2 days and an OLR of $8 \mathrm{~kg} \mathrm{COD} \mathrm{m}^{-3} / \mathrm{dmaximum}^{-3}$ rate of removal was found to be $5.2 \mathrm{~kg} \mathrm{COD} \mathrm{m}^{-3} / \mathrm{d}$ (Oktem et al., 2007). A UASR operating in thermophillic mode $\left(55^{\circ} \mathrm{C}\right)$ showed a high $\mathrm{COD}(65-75 \%)$ and BOD removal (80-94\%) even at high OLR of $9 \mathrm{~kg} \mathrm{COD} \mathrm{m}^{-3} / \mathrm{d}_{\text {(Sreekanth }}$ et al., 2009). Carbamazapine, however, was not degraded using a UASR.

\section{Physio-chemical treatment options}

As seen in oxidation reactionssection, conventional wastewater treatment systems can be effective in removing some, but not all pharmaceuticals from wastewater. Therefore, other treatment technologies have been explored with the intention of finding suitable polishing techniques to further reduce pharmaceuticals concentrations. These technologies include membrane separation, chemical removal, activated carbon, chlorination, ultraviolet irradiation and other novel approaches. The efficiency of these methods for the treatment of pharmaceutical wastewater varies significantly and is described below.

\section{Membrane processes}

Several membrane types and applications were evaluated for the removal of APIs at pilot and fullscale, including microfiltration, ultra filtration, nanofiltration, reverse osmosis, electro dialysis reversal, membrane bioreactors and combinations of membranes in series (Bellona and Drewes, 2007; Snyder et al., 2007). Microfiltration and ultra filtration are generally not fully effective in removing organic contaminants as pore sizes vary from 100-1000 times larger than the micro pollutants which can slip through the membranes.

The pressure-driven membrane processes Nanofiltration (NF) and Reverse osmosis (RO) have been the focus of attention of many researchers for the treatment of drinking water (Watkinson et al., 2007). However, the studies on the use of RO/NF for pharmaceutical removal is limited and most of the studies employed NF and RO membranes for tertiary treatment in wastewater recycling plant or for treating saline groundwater. (Nghiem et al., 2005; Yoon et al., 2006; Snyder et al., 2007). RO in different configurations showed efficient removal of thirty-six personal care products and endocrine disrupting chemicals including antibiotics, lipid regulators, hormones and oral contraceptives, antiepileptics and analgesics (Snyder et al., 2007; Watkinson et al., 2007).

RO membranes removed the majority of compounds investigated to levels below the limit of detection. However, pentoxifylline, iodopromide, dimethyltoluamide (DEET), meprobamate, phosphanetriyltripropanoic acid (TCEP), gemfibrozil, musk ketone and oxybenzone were detected in the permeate of a variety of the configurations (Snyder et al., 2007). A possible reason for this is short circuiting of the membrane or the failure of membrane support media. (Bellona et al., 2004). Radjenovic et al. (2007) investigated the removal of a range of pharmaceuticals including hydrochlorothiazide, 
ketoprofen, diclofenac, propyphenazone and carbamazepine using NF and RO technologies for a fullscale drinking water treatment plant, with high rejection percentages $(>85 \%)$ for all the pharmaceuticals reported. Pharmaceuticals can be rejected on NF and RO membranes by one or a combination of three basic mechanisms: size exclusion (sieving, steric effect), charge exclusion (electrical) and physico-chemical interactions between solute, solvent and membrane. In laboratory-scale cross-flow tests with NF-90 membranes rejections of ketoprofen and diclofenac were reported to be greater than $90 \%$ (Amy et al., 2005; Xu et al., 2005). In another study with RO membranes the retention of negatively charged diclofenac was $95 \%$ (Kimura et al., 2003). Some studies reported higher removal efficiencies of polar and charged compounds in NF/RO processes due to interactions with membrane surfaces (Ozaki and Li, 2002; Bellona et al., 2004; Amy et al., 2005; Braeken et al., 2005). Though both NF and RO treatment shows potential as an efficient method for removing pharmaceuticals from the wastewater, the disposal of the sludge which could contain the pollutant in a more concentrated form remains.

\section{Activated carbon (AC)}

$\mathrm{AC}$ is a recognised conventional technology for the removal of both natural and synthetic organic contaminants (Hrubec et al., 1983; Annesini et al., 1987). It is most commonly applied as a powdered feed or in granular form in packed bed filters. Granular activated carbon (GAC) can be used as a replacement for anthracite media in conventional filters, providing both adsorption and filtration. It can be applied following conventional AS treatment as an adsorption bed. However, carbon regeneration and disposal are environmental considerations (Snyder et al., 2007).

In general, sorption is described using Freundlich isotherms, with sorption behaviour quantified as the specific sorption coefficient, $\mathrm{K}_{\mathrm{D}}(\mathrm{L} / \mathrm{mg}$ ) (Nagaoka et al., 2002; Li et al., 2005). This coefficient is the ratio of equilibrium concentrations of a dissolved compound in a system containing a sorbent (AC or sludge or solids) and an aqueous phase and expressed as:

$$
K_{D}=\frac{C_{s}^{a d s}(e q)}{C_{a w}^{a d s}(e q)}
$$

Where $\mathrm{C}_{\mathrm{s}}$ ads $(\mathrm{eq})$ is the amount of the compound sorbed on the sorbent at sorption equilibrium $(\mathrm{mg} / \mathrm{g})$, and $\mathrm{C}_{\mathrm{aw}}$ ads $(\mathrm{eq})$ is the concentration of the compound in the aqueous phase at sorption equilibrium $(\mathrm{mg} / \mathrm{L})$. Sorption is negligible for substances with $\log \mathrm{K}_{\mathrm{D}}$ values less than 2 , but is large when the $\log \mathrm{K}_{\mathrm{D}}$ value is greater than 4 (Clara et al., 2005). The reported Log $\mathrm{K}_{\mathrm{D}}$ values of estrogens like Estrone, $17 \beta$-Estradiol and $17 \alpha$-Ethinylestradiol ranged from 2.2 to 2.8 (Carballa et al., 2008) and 2.0 to 2.84 (Ternes et al., 2004), respectively. Since these $\log \mathrm{K}_{\mathrm{D}}$ values are between 2 and 4 , sorption can be suitable as a removal mechanism. Dutta et al. (1997) studied the adsorption and desorption of 6-aminopenicillanic acid (6-APA) in aqueous solution using activated carbon. They found that the adsorption process was highly reversible, the extent of reversibly adsorbed 6-APA was around $93 \%$.

Snyder et al. (2007) found that both powdered activated carbon (PAC) $(5 \mathrm{mg} / \mathrm{L})$ and GAC removed greater than $90 \%$ of estrogens (100-200 ng/L initial concentrations). However, dissolved organic compounds, surfactants and humic acids compete with binding sites and can block pores within the AC structure (Zhang and Zhou, 2005; Snyder et al., 2007). PAC, which was used at pilot scale, achieved greater than $90 \%$ removal for 19 of 26 APIs tested including trimethoprim, carbamezapine and acetaminophen. Poor results were seen where regular regeneration was not provided. The filtration step prior to the treatment of micro pollutants by PAC is important (Hartig et al., 2001). The general difficulty with PAC treatment lies in separating the carbon from the water. Various options are available: it can be done either via sedimentation, which necessitates the use of precipitants, or via (membrane) filtration, which requires additional energy. PAC performance can also be improved by increasing the retention time (Westerhoff et al., 2005; Yoon et al., 2005). The filtration step reduces the carbon demand of the wastewater due to reduced blocking of the micropores by high molecular weight compounds. Consequently PAC is only suitable for the treatment of pre-treated wastewaters or wastewaters with a low organic loading.

\section{Chlorination}

Chlorination has been shown to be effective for the removal of pharmaceuticals including $17 \alpha-$ ethinylestradiol and $17 \beta$-estradiol (Alum et al., 2004) and sulfonamides (Qiang et al., 2006). Chlorine dioxide 
is also effective for the removal of sulfamethoxazole, roxithromycin, $17 \alpha$-ethinylestradiol and diclofenac (Khetan and Collins, 2007). Chlorination and ozonation when compared for the removal of bisphenol A, 17 $\beta$ estradiol, and $17 \alpha$-ethinylestradiol and byproduct estrogenicity from distilled water showed comparable results with ozonation resulting in 75-99 \% removal (Alum et al., 2004). Residual chlorine and ozone was found to be low with $>99 \%$ loss of the parent compound (Gharbani et al., 2010).

Lee and Von Gunten (2009) achieved $90 \%$ conversion of estrogen, $17 \alpha$-Ethinylestradiol with chlorine and increased the rate of $17 \beta$-Ethinylestradiol transformation by a factor of 3 with the addition of 0.25 $\mathrm{mM} \mathrm{Br}$. The accelerating effect of $\mathrm{Br}^{-}$diminishes in the presence of dissolved organic matter as it consumes bromine faster than estrogens (Flores and Hill, 2008). Acetaminophen, diclofenac, sulfamethoxazole and fluoroquinlone all become oxidised during chlorination. By-products of acetaminophen include the toxic byproducts $N$-acetyl- $p$-benzoquinine imine and 1,4-benzoquinone. Both metoprolol and sulfamethoxazole form carcinogens such as chloramines as one of their oxidation products and this may be due to the fact that ammonia chlorination was about one thousand times faster than phenol chlorination (Pinkston and Sedlak, 2004).

\section{Oxidation reactions}

The biological and physiochemical treatment methods described previously have shown limited success for the treatment of pharmaceutical wastewater. However, the development of oxidation processes is showing higher removal rates. Oxidation reactions have primarily been used to supplement rather than replace conventional systems and to enhance the treatment of refractory organic pollutants (Balcioglu and Otker, 2003). This technology has been successfully applied to the treatment of pharmaceuticals (Khetan and Collins, 2007). A chemical agent such as hydrogen peroxide, ozone, transition metals and metal oxides are required for AOPs. In addition, an energy source such as ultraviolet-visible radiation, electric current, gamma-radiation and ultrasound is required (Ikehata et al., 2006). AOPs are based on the production of free radicals, in particular the hydroxyl radical and facilitate the conversion of pollutants to less harmful and more biodegradable compounds (Ikehata et al., 2006). AOPs frequently include ozonation coupled with hydrogen peroxide and Ultraviolet (UV) irradiation. Fenton and $\mathrm{TiO}_{2}$ photocatalysis are also employed. Heterogeneous mixtures of ozone, hydrogen peroxide, Fenton and titanium dioxide in light and dark have revealed a range of suitable treatment methods depending on the properties of the phammaceuticals and economic considerations.

The ultimate aim of AOPs is the mineralisation of pollutants, with conversion to carbon dioxide, water, nitrogen and other minerals. Various studies have confirmed the potential of AOPs for removing pharmaceuticals (Ternes et al., 2002; Huber et al., 2003). AOPs may change a compound's polarity and the number of functional groups which affect the functionality of the pharmaceutical in the body. Original medicinal modes of action should then disappear e.g. antibiotics which have been hydroxylated should not promote the formation of resistant strains (Ternes et al., 2003). However, degradation compounds must be identified and monitored as they may be more toxic that the parent compounds (Vogna et al., 2002). Photocatalytic degradation studies using the analgesic anxiolytic drug, buspirone, have revealed that the intermediates produced reflect those found in biotransformation in animal models (Calza et al., 2004). Methods that produce fewer intermediates must to allow for effective modelling and application are being developed (Gaya and Abdullah, 2008).

Photo initiated AOPs may be coupled with other biological, physical and chemical methods for mineralisation. Pre-treatments such as micro or ultra filtration, reverse osmosis followed by an AOP have proved effective for the treatment of industrial wastewater (O1lis, 2003). AOPs may enhance biodegradability as a pre-treatment method to biological treatment (Oller et al., 2007) or as a tertiary treatment. AOPs also handle fluctuating flow rates and compositions with less difficulty than microbes, as the same level of adaptation to the wastewater is not necessary (Ikehata et al., 2006). Cost of both the chemical agent and the energy source can be a major block to implementation of AOPs on an industrial scale (Legrini et al., 1993). However, by using solar irradiation the capital cost of AOPs may be substantially reduced (Trovo et al., 2008). Natural compounds as well as carbonate, bicarbonate and chloride ions may lead to a reduction in treatment efficiency as these compounds may act as antioxidants (Ikehata et al., 2006). 


\section{Ozonation}

Ozone has been applied to the treatment of waters primarily due to its strong disinfection and sterilisation properties (Araña et al., 2002). Its application for the treatment of waters containing pharmaceutical residues is now a broad area of research (Balcioglu and Okter, 2003; Ternes et al., 2003; Andreozzi et al., 2005; Huber et al., 2005; Andreozzi et al., 2006; Nakada et al., 2007; Dantes et al., 2008). The main mode of action in the ozonation process is the formation of $\mathrm{OH}^{-}$radicals due to ozone decay in the water, but there are also ozone molecules present for chemical attack. This increases the oxidation capacity (Ternes et al. 2003). Ozonation has been implemented as the principle treatment method or to enhance the biodegradability and efficiency of subsequent treatment (Cokgor et al., 2004). Ozone production is an energy intensive process, making it costly to implement. An ozone treatment system may increase the energy demand over a conventional wastewater treatment plant by $40-50 \%$ (Larsen et al., 2004). The use of ozone as a means of breaking down pharmaceuticals in water has been the subject of numerous studies over the last ten years including (Andreozzi et al., 2003a; b; Vogna et al., $2004 \mathrm{a}$; b). A significant contribution to this work has been in the area of antibiotic removal (Balcioglu and Okter, 2003; Ternes et al., 2003; Andreozzi et al., 2005; Andreozzi et al., 2006; Dantes et al., 2008), where removal rates $>90 \%$ have been reported. However, the reported removal rate for lipid regulators is less at about $50 \%$ and about $60-80 \%$ for $\beta$-blockers and below $50 \%$ for some Antiphlogistics (Ternes et al., 2003).

Although the degree of removal and mineralisation of pharmaceuticals in water or synthetic industrial effluent has been reported, little or no literature exists on the ozonation of pharmaceuticals in actual pharmaceutical wastewater (Cokgor et al., 2004). Furthermore details of process optimisation and kinetics for the elimination of pharmaceuticals using ozone are limited (Arslan-Alaton and Caglayan, 2005). Also, disagreement exists for the ozone dose necessary for pharmaceutical removal. Ternes et al. (2003) reports almost complete removal of pharmaceuticals except for iopromide in a study using an ozone dose of 10 to 15 $\mathrm{mg}$ for every litre wastewater (contact time $18 \mathrm{~min}$ ) treated in a municipal WWTP. On the other hand, Huber et al., (2003) pointed out, that only about $2 \mathrm{mg} / \mathrm{L}$ of ozone was needed to oxidise a range of pharmaceuticals (among them diclofenac and sulfamethoxazole) to a removal rate of 90 to $99 \%$. In general, both studies demonstrated that the increased pharmaceutical oxidation increased with ozone levels. The amount of ozone required depends on various parameters, such as the level of background dissolved organic matter and wastewater $\mathrm{pH}$ and alkalinity, as well as the desired elimination performance (Huber et al., 2005). The results of the various studies indicate that ozonation of pharmaceuticals depends on their chemical structure. While compounds with a $\mathrm{C}=\mathrm{C}$ bond or aromatic structures seem to be susceptible to ozonation, compounds with amide structures are resistant to it (Nakada et al., 2007).

Recent kinetic studies on pharmaceuticals including amoxicillin, lincomycin, clofibric acid, acetaminophen, bisphenol A, 17-estradiol, and 17-ethinylestradiol have shown ozone to attack aromatic rings and amino groups (Andreozzi et al., 2003a; b; 2005; Arslan-Alaton and Caglayan, 2005; Andreozzi et al., 2006). A kinetic study of the effect of such an ozone attack on the antibiotic amoxicillin showed direct attack on the phenolic ring leading to the formation of hydroxyl derivative intermediates, with no evidence of oxidation of the sulphur atom (Andreozzi et al., 2005). Another kinetic analysis of the effect of 5-10 $\mathrm{mg} \mathrm{O}_{3} / \mathrm{L}$ on four beta blockers, (acebutolol, atenolol, metoprolol and propranolol) from reverse osmosis permeate also showed that ozone can attack aromatic rings and amine groups (Benner et al., 2008). The reaction of the aromatic structure is independent of solution $\mathrm{pH}$. However amine groups do not react directly with ozone and so the reactivity of amines strongly depends on the $\mathrm{pKa}$ of the amine and the $\mathrm{pH}$ of the solution. As with all oxidation processes, the degradation products must be analysed as they may be more toxic than the parent compound (Andreozzi et al., 2006; Ikehata et al., 2006). It also must be considered that other compounds in the waste stream other than the target pharmaceutical may produce more harmful by-products as a consequence of the ozonation process. The main disadvantage of ozonation is that in general the target compounds are not fully mineralised, but merely transformed, and so even more harmful substances can be produced as a result. For example, Microtox analysis showed a slight increase in acute toxicity in the first stage of ozonation of sulfamethoxazole (Dantes et al., 2008). Therefore, an additional treatment such as sand filtration is required after ozonation to break down reactive oxidation products. However, as well as 
removing micro pollutants, ozone reduces not only the microbial count but also odour, colour and foam. At the same time, it is associated with higher energy costs as described above (Larsen et al., 2004).

\section{Perozonation}

Perozonation, a combination of hydrogen peroxide and ozone, has been successfully used to degrade penicillin formulation effluent (Balcioglu and Okter, 2003; Arslan-Alaton et al., 2004; Cokgor et al., 2004). The conjugate base of $\mathrm{H}_{2} \mathrm{O}_{2}$ at low concentrations increases the rate of decomposition of $\mathrm{O}_{3}$ into hydroxyl radicals (Balcioglu and Okter, 2003). $30 \%$ removal of COD in penicillin formulation effluent was accomplished using ozonation alone (Arslan-Alaton et al., 2004). Removal efficiency was enhanced through the addition of $\mathrm{H}_{2} \mathrm{O}_{2}$, to a maximum of $76 \%$ in the presence of $2 \mathrm{mM}_{\text {of }} \mathrm{H}_{2} \mathrm{O}_{2}$. However, it was found that a certain fraction of the resulting COD was non-biodegradable in the subsequent biotreatment. This inert fraction of the waste remained in the effluent. Only overall COD loading was monitored and not actual penicillin levels or breakdown compounds (Arslan-Alaton et al., 2004). Thus, the true treatment efficiency of the method in terms of the penicillin removal was unclear. Cokgor et al. (2006) investigated the pretreatment of synthetic penicillin formulation effluent containing procain penicillin $\mathrm{G}(\mathrm{PPG})$ with the $\mathrm{O}_{3} / \mathrm{H}_{2} \mathrm{O}_{2}$ process (applied ozone dose $=1440 \mathrm{mg} / \mathrm{h}$ treatment time $=60 \mathrm{~min} ; \mathrm{pH} 7 ; \mathrm{H}_{2} \mathrm{O}_{2}=10 \mathrm{mM}$ ). The effect of chemical pretreatment was assessed on the basis of acute toxicity and biodegradability with activated sludge using water flea Daphnia magna toxicity. The pretreatment resulted in more than $70 \% \mathrm{COD}$ removal and a $50 \%$ decrease in the acute toxicity towards Daphnia magna.

Other studies involving penicillin showed COD and aromaticity results increased from $69 \%$ and $29 \%$ for ozone alone to $95 \%$ and $90 \%$ in the presence of $20 \mathrm{mM}$ hydrogen peroxide (Balcioglu and Okter, 2003). The presence of UV increased the COD removal in penicillin formulation wastewater to almost $100 \%$. For synthetic formulation effluents containing the antibiotics like ceftriaxone and enrofloxacin, only slight increases in efficiency were noted following the addition of hydrogen peroxide (Cokgor et al., 2006).

Combined $\mathrm{UV}, \mathrm{O}_{3}$ and $\mathrm{H}_{2} \mathrm{O}_{2}$ treatment was applied to a municipal wastewater treatment plant effluent containing seventeen pharmaceuticals including antibiotics, $\beta$-blockers, antiepileptics, antiphlogistics and lipid lowering agents at a German Municipal WWTP
(Ternes et al., 2003). Removal of all target analytes below detection limits was noted following 18 min contact time at an ozone dose of $10-15 \mathrm{mg} / \mathrm{L}$, with the exception of the iodinated X-ray contrast media, diatrizoate, iopamidol, iopromide and iomeprol which showed removal efficiencies of not higher than $14 \%$. Diatrizoate was removed by only $25 \%$ following $10 \mathrm{mg} / \mathrm{L} \mathrm{O}_{3}$. The addition of $\mathrm{H}_{2} \mathrm{O}_{2}$ only slightly increased removal efficiency. The removal rates for a variety of pharmaceuticals using hydrogen peroxide show efficiencies ranging from $40 \%$ for Acetominophen (Andreozzi et al., 2003b) to $>95 \%$ removal for some hormones when combined with UV (Rosenfeldt and Linden, 2004).

\section{Fenton reactions}

Fenton chemistry involves reactions of hydrogen peroxide in the presence of iron to generate hydroxyl radicals (Carey, 1992). Ultraviolet light enhances this generation by the photo reduction of Fe (III) to Fe (II). Since iron is abundant and non-toxic, Fenton reactions are a viable option for wastewater treatment. PhotoFenton reactions have been used for the degradation of diclofenac (Ravina et al., 2002; Perez-Estrada et al., 2005b). Complete mineralisation of diclofenac and its intermediates via photo-Fenton reactions in a concentric photo reactor took approximately $50 \mathrm{~min}$ (Ravina et al., 2002). Compound parabolic collectors have also been used to mineralise diclofenac in approximately $60 \mathrm{~min}$. Another advantage of Fenton reactions is that mineralisation is possible in sunlight avoiding the use of UV light (Pérez-Estrada et al., 2005a). Fenton $\left(\mathrm{Fe}^{2+} /\right.$ $\left.\mathrm{H}_{2} \mathrm{O}_{2}\right)$ and Fenton-like $\left(\mathrm{Fe}^{3+} / \mathrm{H}_{2} \mathrm{O}_{2}\right)$ reactions were compared for both dark and photo-assisted reactions (Arslan-Alaton and Dogruel, 2004). Penicillin was completely removed after 40 min of advanced oxidation with $\mathrm{Fe}^{2+} / \mathrm{H}_{2} \mathrm{O}_{2}$ at $\mathrm{pH}$ 3. Higher $\mathrm{COD}$ and Total organic carbon (TOC) removals were obtained with dark $\mathrm{Fe}^{2+}$ / $\mathrm{H}_{2} \mathrm{O}_{2}$ at $\mathrm{pH} 3$ compared with dark Fenton-like $\mathrm{Fe}^{3+} / \mathrm{H}_{2} \mathrm{O}_{2}$ (Arslan-Alaton and Dogruel, 2004). Photo-assisted reactions using UV-C provided only slightly higher removal efficiencies. TOC removal was higher with photo-Fenton reaction and COD removal was slightly higher with photo-Fenton-like reactions.

Since Fenton reactions operate at room temperature normal pressure and without the highly complicated apparatus, there should be a smooth transition from laboratory scale to large scale (Kavitha and Palanivelu, 2004). On the other hand, the strong dependence on 
the aqueous solution $\mathrm{pH}$ (optimum $\mathrm{pH}$ 2-4 for the production of $\mathrm{OH}$. radicals) and on the concentrations of hydrogen peroxide and ferric / ferrous ions and the disposal of the iron sludge are factors which need to be taken into consideration (Shemer et al., 2006). One possibility is the partial use of Fenton reactions to produce a non-toxic and biodegradable intermediate which could then be treated in an inexpensive biological step to achieve complete mineralisation (Munoz et al., 2006).

\section{Direct photolysis}

Direct photolysis occurs due to the breakdown of a compound by the absorption of light. Indirect photolysis is caused when photosensitisers, such as nitrate and dissolved organic matter, absorb light and generate reactive oxygenated radicals that subsequently degrade other compounds (Legrini et al., 1993). Many pharmaceuticals are readily susceptible to photolytic transformation. APIs that do not absorb light above $290 \mathrm{~nm}$ are more resistant to direct photolysis with natural light (Khetan and Collins, 2007). Lamps employed in the removal of micropollutants focus mainly on low and medium pressure mercury lamps. Low pressure mercury lamps characteristically generate light at $254 \mathrm{~nm}$ while medium pressure lamps emit their energy at multiple wavelengths (Takashi et al., 2007). Using a 110W, $254 \mathrm{~nm}$ UV lamp at $313 \mathrm{~K}$ and $0.5 \mathrm{~g} / \mathrm{L}$, a $70 \%$ conversion of $0.25 \mathrm{~L}$ of 2 -chloropyridine (typically found in effluent of pharmaceutical processing) was achieved in $20 \mathrm{~min}$ (Stapleton et al., 2006). Mefenamic acid was observed to undergo direct photolysis with a half-life of $33 \mathrm{~h}$ under direct noon sunlight in mid-October at $45^{\circ}$ latitude (Werner et al., 2005). Carbamazepine and clofibric acid have photodegradation half-life times of $100 \mathrm{~d}$ in winter at $50^{\circ} \mathrm{N}$. Conversely sulfamethoxazole, diclofenac, ofloxacin and propranolol undergo faster degradation with half-lives of 2.4, 5.0, 10.6 and 16.8 days, respectively. In a different set of experiments, clofibric acid, diclofenac, fenoprofen, isopropylantipyrine, ketoprofen, phenytoin and triclosan were removed in a laboratory situation ( $>96 \%$ ) by ultraviolet photolysis alone (Giri et al., 2011). A fundamental parameter that determines the rate of degradation for photolysis is the decadic molar absorption coefficient. The decadic molar extinction coefficient is a measure of the capacity of a compound to absorb light. Ibuprofen, diphenhydramine, phenazone, and phenytoin have decadic molar extinction coefficients of $256 / \mathrm{M} / \mathrm{cm}, 388 /$ $\mathrm{M} / \mathrm{cm}, 8906 / \mathrm{M} / \mathrm{cm}$ and phenytoin $1260 / \mathrm{M} / \mathrm{cm}$, respectively. As indicated by the decadic molar extinction coefficients, $27.4 \%$ removal of $5 \mu \mathrm{m}$ initial concentration of ibuprofen, $26.34 \%$ of diphenhydramine, $95.78 \%$ and $87.75 \%$ degradation for phenazone and phenytoin, respectively, was observed (Yuan et al., 2009). The experiment was carried out using a $11 \mathrm{~W}$ low pressure lamp producing monochromatic UV light at $254 \mathrm{~nm}$ in a $500 \mathrm{~mL}$ quartz reactor. The antibiotic metronidazole achieved only $6 \%$ removal with a low-pressure and $12 \%$ with a medium pressure mercury lamp after 5 min exposure. Metronidazole has a crucial absorption centered at about $310 \mathrm{~nm}$, which can be readily excited by a medium pressure lamp. In contrast, low pressure lamps only emit light at $254 \mathrm{~nm}$ and as a result, the important absorption at $310 \mathrm{~nm}$ is missed. The adsorption-lamp emission mismatch consequently explains the low removal with UVC light (Yuan et al., 2009). As such, direct photolysis on its own is not an effective for removing pharmaceuticals from wastewater. Alternatively, photolysis coupled with $\mathrm{Fe}$ (III) and $\mathrm{H}_{2} \mathrm{O}_{2}$ or $\mathrm{TiO}_{2}$ can remove over $98 \%$ of pharmaceuticals including estrogens (Feng et al., 2005; Benotti et al., 2009).

\section{$\mathrm{TiO}_{2}$ photocatalysis}

Photocatalysis is the acceleration of a photochemical transformation by the action of a catalyst such as $\mathrm{TiO}_{2}$ or Fenton's reagent (Chatterjee and Dasgupta, 2005; Herrmann, 2005; Dalrymple et al., 2007). Most photocatalysts are semiconductor metal oxides which characteristically possess a narrow band gap. Radicals formed degrade impurities in the water relatively unselectively, reacting with impurities in the wastewater as well as the target pharmaceuticals (Lhomme et al., 2008). Since the degradation of chlorobipenyls and biphenyls from aqueous media using $\mathrm{TiO}_{2}$ photocatalysis was first reported (Carey et al., 1976) the number of publications on the removal of micropollutants from aqueous media using $\mathrm{TiO}_{2}$ has grown considerably (Doll and Frimmel, 2005a, b, c; Pérez-Estrada et al., 2005a). Titania is the most widely investigated of the heterogeneous photocatalyst due to its cost effectiveness, inert nature and photostability (Gaya and Abdullah, 2008). Investigations into the removal of the pharmaceuticals using $\mathrm{TiO}_{2}$, include but are not limited to work on 
antibiotics, lipid regulators, x-ray contrast media, antiepileptics and antiphlogistics (Doll and Frimmel, 2005a, b and c; Perez-Estrada et al., 2005a). Removal rates have been reported at $98 \%$ for antibiotics when used in combination with UV (Addamo et al., 2005). However, removal rates for carbamazepine are under $10 \%$ (Doll and Frimmel, 2005a). $\mathrm{TiO}_{2}$ is available at a relatively modest price and would be recyclable in an industrial application when fixed on films or beads, reducing the quantities of $\mathrm{TiO}_{2}$ required (Legrini et al., 1993). Furthermore, solar studies have proved effective for a wide range of pharmaceuticals replacing the expense of generating UV light. There are difficulties in implementation on a commercial scale due to the number of operating parameters e.g. type and geometry of reactor, the photocatalyst, optimum energy use and wavelength of radiation. Moreover, it is difficult to assess the true success of the photocatalytic process in the absence of identified intermediate compounds and end products.

\section{Photocatalytic reactors and reaction kinetics}

In the development of photocatalytic reactors, many factors need to be considered including mass transfer, reaction kinetics, mixer, catalyst installation and catalyst illumination. Based on the arrangement of the light source, reactor configurations can be categorised as: 1) immersion type where lamps are inserted into the reactor, and 2) external type where lamps are put outside the reactor (Ray, 1998). One of the major impediments to the commercialisation of photocatalytic water treatment is the high cost of generating artificial radiation. Therefore, solar photocatalytic reactors have received considerable interest. To ensure efficient conversion of the incident solar radiation to charge carriers, the design of the solar reactor is extremely important. There are four frequently used reactor configurations: Parabolic trough reactor (PTR), Thin film fixed bed reactor (TFFBR), Compound parabolic collector (CPC) and Double skin sheet reactor (DSSR) (Bahnemann, 2004). PTRs concentrate sunlight into a focal line using parabolic mirrors. A TFFBR consists of a sloping plate coated with the photocatalyst and rinsed with the polluted water in a very thin film. The DSSR is a flat and transparent structured PLEXIGLAS ${ }^{\circledR}$ box. The polluted water and the photocatalyst can be pumped through channels in the box. A CPC is a combination of parabolic concentrators and flat static systems. Reactors can also be classified into concentrating and non-concentrating. These two types of reactors are compared in Table 1. CPCs are low concentration collectors which are a good option for solar photocatalysis since they combine the better features of concentrating and non-concentrating collectors and none of the disadvantages. The photoreactor is tubular so that water can be pumped easily. CPCs use direct and diffuse solar radiation efficiently without solar tracking. The water does not heat up and there is no evaporation of volatile compounds (Malato et al., 2007).

Table 1: Comparison of reactor types (Bockelmann et al., 1995; Malato et al., 2007)

\begin{tabular}{|c|c|c|}
\hline Example & $\begin{array}{l}\text { Concentrating } \\
\text { PTR }\end{array}$ & $\begin{array}{l}\text { Non-concentrating } \\
\text { TFFBR, DSSR and CPC }\end{array}$ \\
\hline Advantages & $\begin{array}{l}\text { Turbulent flow conditions which favour mass transfer } \\
\text { and avoid catalyst sedimentation problems } \\
\text { Two axis sun tracking system } \\
\text { Nearly closed reactor-no vaporisation of volatile } \\
\text { contaminants } \\
\text { Smaller reactor tube area which is able to support higher } \\
\text { pressures and a large amount of area per unit volume }\end{array}$ & $\begin{array}{l}\text { Total global irradiation is usable } \\
\text { High optical efficiency } \\
\text { Low manufacturing costs due to its simple } \\
\text { construction } \\
\text { No additional } \mathrm{H}_{2} \mathrm{O}_{2} \text { necessary since there is } \\
\text { effective transfer of air into the water film. } \\
\text { High quantum efficiency } \\
\text { No heating needed }\end{array}$ \\
\hline Disadvantages & $\begin{array}{l}\text { Only direct irradiation can be used } \\
\text { Low optical efficiency } \\
\text { Since sun-tracking is needed there are high investment } \\
\text { costs } \\
\text { The } \mathrm{TiO}_{2} \text { needs to be separated from the purified water } \\
\text { Water over-heating can lead to leaks and corrosion } \\
\text { Additional } \mathrm{H}_{2} \mathrm{O}_{2} \text { may be needed }\end{array}$ & $\begin{array}{l}\text { The volatile reactants can vaporise } \\
\text { The catalyst is not protected from pollution } \\
\text { A large catalyst area is needed when purifying } \\
\text { large volumes of wastewater } \\
\text { There is low mass transfer due to the laminar } \\
\text { flow conditions } \\
\text { Requires significantly more photoreactor area }\end{array}$ \\
\hline
\end{tabular}


The DSSR and the CPC were compared for their treatment of dichloroacetic acid as a model pollutant. Using $5 \mathrm{~g} / \mathrm{L}$ Hombikat UV 100 as the photocatalyst, the TOC decreased from 51.1 to $16.8 \mathrm{mg} / \mathrm{L}$ in the DSSR and from 51.6 to $18.4 \mathrm{mg} / \mathrm{L}$ for the $\mathrm{CPC}$ within $150 \mathrm{~min}$. The ratio of the kinetic parameters, $\mathrm{k}_{3 \mathrm{cpc}} / \mathrm{k}_{3 \mathrm{dssr}}$ values indicate that the DSSR was slightly more efficient than the CPC. This ratio (smaller than 1 in almost all cases) reflects the different ability of the photo reactors to utilise the available light (Dillert et al., 1999).

Four different reactors -PTR, CPC, Tubular collector (TC) and V shaped trough collector (VC)- were compared for their ability to degrade oxalic acid in an aqueous suspension of $\mathrm{TiO}_{2}$ (Bandala et al., 2004). The performance of the four detectors is quite similar in terms of energy accumulated however the TC produced the least degradation.

CPCs have also been used to compare heterogeneous solar photocatalysis and solar photoFenton reactions for the degradation of methylphenylglycine (MPG) contaminated wastewaters (Munoz et al., 2006). A Life cycle assessment (LCA) was done whereby the environmental impact was assessed by identifying and quantifying energy and materials usage and waste discharge impacts and evaluation of opportunities for environmental improvements over the whole life cycle. While both processes degraded the MPG from 500 to $0 \mathrm{mg} / \mathrm{L}$, the environmental performance of solar photo-Fenton coupled to biological treatment was $80-90 \%$ better than that of coupled heterogeneous photocatalysis to biological treatment. This was mainly due to the large CPC field $\left(2150 \mathrm{~m}^{2}\right)$ and the electricity consumption of the $\mathrm{TiO}_{2}$ microfiltration required in the photocatalysis experiments. Despite the success of the photocatalytic reactors in removing pollutants, there are a number of problems associated with them. $\mathrm{TiO}_{2}$ is mostly applied in powder form and either has to be separated at the end (which is time-consuming and costly) or immobilised on a rigid support as a thin film (which limits the contact between the reactants and catalyst and thus the reaction rate). A potential solution to this problem is to use a Carberry type photoreactor which combines the advantages of slurry and immobilised photocatalytic systems. It was used to degrade 4- chlorophenol as a model organic compound. Its photocatalytic activity was 3.8 times higher than a configuration of two $\mathrm{TiO}_{2}$ slides (which served as an approximation of a TFFBR) (Cernigoj et al., 2007). Other reactors with increased performance include the optical fiber reactor (Danion et al., 2004), corrugated plate reactor (Zhang et al., 2004), fountain reactor with a parabolic profile (Puma et al., 2001), Taylor vortex reactor (Dutta and Ray, 2004), fluidised photo reactors (Lee et al., 2003), Spinning disc reactor (Yatmaz et al., 2005) and labyrinth flow photoreactor with immobilised $\mathrm{TiO}_{2}$ bed (Mozia et al., 2005). Most of the work to date on photoreactors has been on a laboratory scale, with only a limited number of large-scale applications of photocatalysis to wastewater treatment. Doll and Frimmel (2005a) investigated the combination of semiconductor photocatalysis with cross-flow microfiltration, which allowed the separation and reuse of $\mathrm{TiO}_{2}$ after the photocatalytic degradation of clofibric acid, carbamazepine, and iomeprol. The majority of other pilot studies have been restricted to experiments with solar-type pilot plant apparatus, specifically those conducted at the Plataforma solar de Almeria (PSA) located in Europe. The efficiency achieved in the laboratory has not been achieved in these larger systems. One of the reasons for this is that small scale studies often fail to take into account the effect of other substances in the wastewaters (Doll and Frimmel, 2005b). Malato et al. (2002) described the experimental systems necessary for performing pilot-plant-scale solar photocatalytic experiments and outlined the basic components of these pilot plants and the fundamental parameters related to solar photocatalysis reactions. The pilot plant has been used successfully to treat pharmaceuticals along with other organic contaminants in wastewater (Perez-Estrada, et al., 2005b). The $\mathrm{TiO}_{2}$ band-gap only represents $5 \%$ of the solar spectrum. Other catalysts may be found which correspond better and could improve the efficiency of photo reactors. Other possibilities are changing catalyst structure and composition, the addition of electron acceptors or doping and deposition with metal ions and oxides (RiosEnriquez and Shahin, 2004). Further research needs to be done in this area for pharmaceutical contaminated waters. In photocatalytic reactions, the contaminant substrate is oxidised by the photo-generated holes or by reactive oxygen species such as the $\mathrm{OH}^{*}$ and $\mathrm{O}^{-}$ radicals formed on the surface of the catalyst. This mechanism requires that the contaminant adsorbs on the catalyst surface as a prerequisite for efficient oxidation (Serpone and Pelizzetti, 1989). Most researchers observe a Langmuir adsorption isotherm and describe the adsorption-desorption process and 
the reaction rate constant based on the associated Langmuir-Hinshelwood (L-H) model (Xu and Langford, 2001; Rao et al., 2003), which is expressed as:

$r=k \theta=-\frac{d C}{d t}=k\left(\frac{K C}{1+K C}\right)$

Where $\mathrm{r}$ is the rate of mineralisation, $\mathrm{k}$ is the reaction rate constant, $\mathrm{C}$ is the concentration, $\mathrm{K}$ is the adsorption coefficient and $\theta$ is the fractional site coverage for the reactant (Herrmann, 1999). In general, adsorption studies are done in the dark and sometimes the adsorption capacity cannot be transferred quantitatively into irradiated systems (Xu and Langford, 2001). Studies indicated that increased adsorption to the catalyst surface translates to increased reaction rates $(\mathrm{Xu}$ and Langford, 2001; Rudder et al., 2004). However, it was found that with little difference in adsorption of carbamazepine on the surface of P25 and Hombikat UV100, the reaction rate and photo-adsorption was much higher with P25 as the catalyst (Doll and Frimmel, 2005b). Although the L-H model seems to adequately describe the macroscopic kinetics when dealing with very dilute aqueous solutions of photodegradable contaminants, some of the inherent assumptions of the model may not be valid at the microscopic level, which includes its failure to account for simultaneous adsorption (or desorption) of parent and intermediate compounds (Cunningham and Al Sayyed, 1990). Clearly, many different types of microscopic mechanisms could lead to the overall L-H type kinetic expression, but the derived kinetic parameters represent fundamentally different reactions and properties (Mandelbaum et al., 1999). Since most pharmaceuticals are present in trace concentrations, generally below $1 \mu \mathrm{mol} / \mathrm{L}(\mathrm{KC}<<1)$, the $\mathrm{L}-\mathrm{H}$ equation simplifies to a pseudo-first-order kinetic equation as follows:

$r=-\frac{d C}{d t}=k_{1} C$ or $C(t)=C_{0} e^{-k_{1} t}$

Where $k_{1}$ is the Pseudo-first-order photo catalytic reaction rate constant. This Pseudo-first-order rate constant is often determined by observing the relative aqueous concentration changes of the contaminant as a function of time during experiments (Wei and Wan, 1992; Doll and Frimmel, 2005a; de Lasa et al., 2006; Tungudomwongsa et al., 2006).

\section{Electrochemical treatment options}

Electrochemistry is a relatively new method for the treatment of wastewater (Chen, 2004). The treatment of acetaminophen using anodic oxidation with a Borondoped diamond (BDD) electrode has been successful during small scale investigations (Brillas et al., 2005). This process allows complete mineralisation of the acetaminophen due to the generation of large concentrations of hydroxyl radicals by the electrode. The BDD electrode was efficient even at low concentrations. BDD has high thermal conductivity, wide band gap, high $\mathrm{e}^{-}$and hole mobilities, high breakdown electric fields, hardness, optical transparency and chemical inertness (Chen, 2004). Ultrasonic irradiation has been considered as a means of removing estrogenic compounds from contaminated water (Belgiorno et al., 2007; Suri et al., 2007). Hormones, for example, estradiol, estrone and ethinylestradiol, were examined in single component batch and flow through reactors using 0.6, 2 and $4 \mathrm{~kW}$ ultrasound sources (Suri et al., 2007). Results showed 80$90 \%$ reduction in the hormones within a $40-60 \mathrm{~min}$ period (Suri et al., 2007). Further investigations in this area would be useful to determine the toxicity of breakdown products and to examine the feasibility of larger scale applications of the technology. Diamond anodes may produce $\mathrm{OH}$ radicals with high current efficiency. This is dependent on the mass transport of organic compounds to the anode not being a limiting factor.

\section{CONCLUSION}

Various treatment methods for pharmaceuticals in water and wastewater found in the literature have contributed greatly to our knowledge regarding the fate of these compounds in different treatment systems. Generalising compound behaviour in these systems would allow further characterisation of the fate and risk associated with pharmaceuticals in the environment, yet this description of trends is hindered by the wide variation in removal efficiencies across therapeutic classes, treatment processes, and even among separate studies for the same individual compounds. The majority of studies summarised used "removal" to describe the elimination of parent pharmaceuticals. The mere disappearance of the parent compound cannot be considered synonymous with complete removal. If adequate controls for physical and chemical removal mechanisms are in place, the loss of the parent compound indicates biotransformation of an unknown degree and not necessarily mineralisation. Only monitoring for metabolites or end 
products of mineralisation can provide information about the degree of biotransformation.

The wastewater from pharmaceutical production facilities and municipal wastewater treatment plant are the primary source of APIs in the environment. A significant amount of research in the area has focused on municipal wastewater, as data from municipal wastewater plants are relatively accessible. However, research into wastewaters from pharmaceutical manufacturing plants is more problematic due to difficulties in accessing information. Nevertheless, treatment technologies that work for municipal wastewaters should also be suitable with modification for industrial wastewaters. There are a number of promising new treatments including AOPs such as oxidation, ozonation, perozonation, direct photolysis, $\mathrm{TiO}_{2}$ photocatalysis, solar photocatalysis, Fenton reactions and ultrasonic irradiation. These significantly enhance the removal rate of pharmaceuticals from wastewaters. Comparisons among these technologies are problematic since most researchers used synthetic water rather than actual wastewater samples. Research is required in this area to improve treatment efficiencies, identify degradation compounds and to determine the cost and feasibility of full-scale applications. There is also interest in coupling AOPs with more conventional treatments such as activated carbon, which is the focus of ongoing research at Dublin City University (Keane et al., 2011; Basha et al., 2010). Finally, the problem of pharmaceuticals in wastewaters cannot be solved - even if it is considerably alleviated - merely by adopting endof-pipe measures. At-source measures like replacement of critical chemicals, reduction in raw material consumption should continue to be pursued as the top priority.

\section{ACKNOWLEDGEMENTS}

The authors wish to thank the QUESTOR Centre (Project: DCU2/07/10) and Science Foundation Ireland (SFI) (Project: 07/RAP/EEEOB7768) for their financial support. Moreover, thanks to: SFI for the STAR award in 2008 and finally the Irish Research Council for Science, Engineering and Technology (IRCSET) for financial support in the form of Ircset Empower postdoctoral fellowship.

\section{REFERENCES}

Addamo, M.; Augugliaro, V.; Paola, A.; García-López, E.; Loddo, V.; Marcì, G.; Palmisano, L., (2005). Removal of drugs in aqueous systems by photoassisted degradation. J. Appl. Electrochem., 35 (7-8), 765-774 (10 pages).

Aguado, D.; Montoya, T.; Borras, L.; Seco, A.; Ferrer, J., (2008). Using SOM and PCA for analysing and interpreting data from a P-removal SBR. Eng. Appl. Artif. Intel., 21 (6), 919930 (12 pages)

Alum, A.; Yoon, Y.; Westerhoff, P.; Abbaszadegan, M., (2004). Oxidation of bisphenol A, 17beta-estradiol, and 17alphaethynyl estradiol and byproduct estrogenicity. Environ. Toxicol., 19 (3), 257-264 (8 pages).

Amy, G.; Kim, T.; Yoon, J.; Bellona, C.; Drewes, J; Pellegrino, J.; Heberer, T., (2005). Removal of micropollutants by NF/ RO membranes. Water Sci. Technol., 5 (5), 25-33 (9 pages).

Andreozzi, R.; Caprio, V.; Marotta, R.; Radovnikovic, A., (2003a), Ozonation and $\mathrm{H}_{2} \mathrm{O}_{2} / \mathrm{UV}$ treatment of clofibric acid in water: a kinetic investigation. J. Hazard. Mater., 103 (3), 233-246 (14 pages).

Andreozzi, R.; Caprio, V.; Marotta, R.; Vogna, D., (2003b), Paracetamol oxidation from aqueous solutions by means of ozonation and $\mathrm{H}_{2} \mathrm{O}_{2} / \mathrm{UV}$ system. Water Res., 37 (5), 993 1004 (12 pages).

Andreozzi, R.; Canterino, M.; Marotta, R.; Paxeus, N., (2005). Antibiotic removal from wastewaters: The ozonation of amoxicillin. J. Hazard. Mater., 122 (3), 243-250 (8 pages).

Andreozzi, R.; Canterino, M.; Giudice, R.; Marotta, R.; Pinto, G.; Pollio, A., (2006). Lincomycin solar photo degradation, algal toxicity and removal from wastewaters by means of ozonation. Water Res., 40 (3), 630-638 (9 pages).

Ankley, G.; Brooks, B.; Huggett, D.; Sumpter, J., (2007). Repeating history: pharmaceuticals in the environment. Environ. Sci. Tech., 41 (24), 8211-8217 (7 pages).

Annesini, M.; Gironi, F.; Ruzzi, M.; Tomei, C., (1987). Adsorption of organic compounds onto activated carbon. Water Res., 21 (5), 567-571 (5 pages).

Araña, J.; Herrera Melián, J.; Doña Rodríguez, J.; González Díaz, O.; Viera, A.; Pérez Peña, J.; Marrero Sosa, P.; Espino Jiménez, V., (2002). $\mathrm{TiO}_{2}$-photocatalysis as a tertiary treatment of naturally treated wastewater. Catal. Today, 76 (2-4), 279-289 (11 pages).

Arslan-Alaton, I.; Caglayan, A., (2005). Ozonation of Procaine Penicillin G formulation effluent Part I: Process optimisation and kinetics. Chemosphere, 59 (1), 31-39 (9 pages).

Arslan-Alaton, I.; Dogruel, S., (2004). Pre-treatment of penicillin formulation effluent by advanced oxidation processes. J. Hazard. Mater., 112 (1-2), 105-113 (9 pages).

Arslan-Alaton, I.; Dogruel, S.; Baykal, E.; Gerone, G., (2004). Combined chemical and biological oxidation of penicillin formulation effluent. J. Environ. Manage., 73 (2), 155-163 (9 pages).

Bahnemann, D., (2004). Photocatalytic water treatment: solar energy applications. Sol. Energy, 77 (5), 445-459 (15 pages).

Balcioglu, I.; Ötker, M., (2003). Treatment of pharmaceutical wastewater containing antibiotics by $\mathrm{O}_{3}$ and $\mathrm{O}_{3} / \mathrm{H}_{2} \mathrm{O}_{2}$ processes. Chemosphere, 50 (1), 85-95 (11 pages).

Bandala, E.; Arancibia-Bulnes, C.; Orozco, S.; Estrada, C., (2004). Solar photoreactors comparison based on oxalic acid photocatalytic degradation. Sol. Energy, 77 (5), 503 512 (10 pages).

Basha, S,; Keane, D.; Nolan, K,; Morrissey, A.; Oelgemoller, M.; Tobin, J., (2010). Studies on the adsorption and kinetics 
of photodegradation of pharmaceutical compound, Indomethacin using novel photocatalytic adsorbents. Ind. Eng. Chem. Res. 49 (22), 11302-11309 (9 pages).

Belgiorno, V.; Rizzo, L.; Fatta, D.; Della Rocca, C.; Lofrano, G.; Nikolaou, A.; Naddeo, V.; Meric, S., (2007). Review on endocrine disrupting-emerging compounds in urban wastewater: occurrence and removal by photocatalysis and ultrasonic irradiation for wastewater reuse. Desalination, 215 (1-3), 166-176 (11 pages).

Bellona, C.; Drewes, J.; Xu, P.; Amy, G., (2004). Factors affecting the rejection of organic solutes during NF/RO treatment-a literature review. Water Res., 38 (12), 2795-2809 (15 pages).

Bellona, C.; Drewes, J., (2007). Viability of a low-pressure nanofliter in treating recycled water for water reuse applications: a pilot-scale study. Water Res., 41 (17), 39483958 (11 pages).

Benner, J.; Salhi, E.; Ternes, T.; von Gunten, U., (2008). Ozonation of reverse osmosis concentrate: Kinetics and efficiency of beta blocker oxidation. Water Res., 42 (12), 3003-3012 (10 pages).

Benotti, M.; Stanford, B.; Wert, E.; Snyder, A., (2009). Evaluation of a photocatalytic reactor membrane pilot system for the removal of pharmaceuticals and endocrine disrupting compounds from water. Water Res., 43 (6), 1513-1522 (10 pages).

Bockelmann, D.; Goslich, R.; Bahnemann, D.; Weichgrebe, D., (1995). Concentrating vs non-concentrating reactors for solar water detoxification. Sol. Energ. Mat. Sol. C, 38 (1-4), 441451 (11 pages).

Braeken, L.; Ramaekers, R.; Zhang, Y.; Maes, G.; Van Der Bruggen, B.; Vandecasteele, C., (2005). Influence of hydrophobicity on retention in nanofiltration of aqueous solutions containing organic compounds. J. Membr. Sci., 252 (1-2), 195-203 (9 pages).

Brillas, E.; Sirés, I.; Arias, C.; Cabot, P.; Centellas, F.; Rodríguez, R.; Garrido, J., (2005). Mineralisation of paracetamol in aqueous medium by anodic oxidation with a boron-doped diamond electrode. Chemosphere, 58 (4), 399-406 (7 pages).

Calza, P.; Pazzi, M.; Medana, C.; Baiocchi, C.; Pelizzetti, E., (2004). The Photocatalytic process as a tool to identify metabolitic products formed from dopant substances: the case of buspirone. J. Pharmaceut. Biomed., 35 (1), 9-19 (11 pages).

Carballa, M.; Fink, G.; Omil, F.; Lema J.; Ternes, T., (2008). Determination of the solid-water distribution coefficient (Kd) for pharmaceuticals, estrogens and musk fragrances in digested sludge. Water Res., 42, (1-2) 287-295 (9 pages).

Carey, J.; Lawrence, J.; Tosine H., (1976). Photo-Dechlorination of PCBs in presence of Titanium-Dioxide in Aqueous Suspensions. B. Environ. Contam. Tox., 16 (6), 697-701 (5 pages).

Carey, J., (1992). An introduction to advanced oxidation processes (AOP) for destruction of organics in wastewater. Water Qual. Res. J. Can., 27 (1), 1-21 (21 pages).

Castiglioni, S.; Bagnati, R.; Fanelli, R.; Pomati, F.; Calamari, D.; Zuccato, E., (2006). Removal of Pharmaceuticals in Sewage Treatment Plants in Italy. Environ. Sci. Tech., 40 (1), 357363 ( 7 pages).

Cernigoj, U.; Urska, L.; Polonca, T., (2007). Evaluation of a novel Carberry type photoreactor for the degradation of organic pollutants in water. J. Photoch. Photobio. A., 188 (2-3), 169-176 (8 pages).
Chang, C.; Chang, J.; Vigneswaran, S.; Kandasamy, J., (2008). Pharmaceutical wastewater treatment by membrane bioreactor process- a case study in southern Taiwan. Desalination, 234 (1-3), 386-392 (7 pages).

Chatterjee, D.; Dasgupta, S., (2005). Visible light induced photocatalytic degradation of organic pollutants. J. Photoch. Photobio. C., 6 (2-3), 186-205 (20 pages).

Chelliapan, S.; Wilby, T.; Sallis, P., (2006). Performance of an up-flow anaerobic stage reactor (UASR) in the treatment of pharmaceutical wastewater containing macrolide antibiotics. Water Res., 40 (3), 507-516 (10 pages).

Chen, G., (2004). Electrochemical technologies in wastewater treatment. Sep. Purif. Tech., 38 (1), 11-14 (4 pages).

Chen , Z.; Nanqi, R.; Wang, A.; Zang, Z.; Shi, Y., (2008). A novel application of TPAD-MBR system to the pilot treatment of chemical synthesis based wastewater. Water Res., 42 (13), 3385-3392 (8 pages).

Clara, M.; Strenn, B.; Gans, O.; Martinez, E.; Kreuzinger, N.; Kroiss, H., (2005). Removal of selected pharmaceuticals, fragrances and endocrine disrupting compounds in a membrane bioreactor and conventional wastewater treatment plants. Water Res., 39 (19), 4797-4807(11 pages).

Cokgor, E.; Alaton, I.; Karahan, O.; Dogruel, S.; Orhon, D., (2004). Biological treatability of raw and ozonated penicillin formulation effluent. J. Hazard. Mater., 116 (1-2), 159-166 (8 pages).

Cokgor, E.; Karahan, O.; Arslan-Alaton, I.; Meric, S.; Saruhan, H.; D., (2006). Effect of Perozonation on Biodegradability and Toxicity of a Penicillin Formulation Effluent, J. Environ. Sci. Heal. A., 41 (9), 1887 - 1897 (11 pages).

Cunningham, J.; Al-Sayyed, G., (1990). Factors influencing efficiencies of $\mathrm{TiO}_{2}$-sensitised photodegradation. Part 1. Substituted benzoic acids: discrepancies with dark-adsorption parameters. J. Chem. Soc. Faraday Trans., 86 (23), 39353941 (7 pages).

Dalrymple, O.; Yeh, D.; Trotz, M., (2007). Removing pharmaceuticals and endocrine-disrupting compounds from wastewater by photocatalysis. J. Chem. Tech. Biotech., 82 (2), 121-134 (14 pages).

Danion, A.; Disdier, J.; Guillard, F.;Abdelmalek, F.; JaffrezicRenault, N., (2004). Characterisation and study of a single$\mathrm{TiO}_{2}$-coated optical fiber reactor. Appl. Catal. B-Environ., 52 (3), 213-223 (11 pages).

Dantes, R.; Contreras, S.; Sans, C.; Esplugas, S., (2008). Sulfamethoxazole abatement by means of ozonation. J. Hazard. Mater., 150 (3), 790-794 (5 pages).

Daughton, C.; Ternes T., (1999). Pharmaceuticals and personal care products in the environment: agents of subtle change. Environ. Health Persp., 107 (S6), 907-938 (32 pages).

De Lasa, H.; Serrano, B.; Salaices, M., (2006). Photocatalytic Reaction Engineering (1st ed.). Springer, New York.

De Wever, H.; Weiss, S.; Reemtsma, T.; Vereecken, J.; Müller, J.; Knepper, T.; Rörden, O.; Gonzalez, S.; Barcelo, D.; Hernando, M., (2007). Comparison of sulfonated and other micropollutants removal in membrane bioreactor and conventional wastewater treatment. Water Res., 41(4), 935945 (11 pages).

Dillert, R.; Cassano, A.; Goslich, R.; Bahnemann, D., (1999) Large scale studies in solar catalytic wastewater treatment. Catal. Today, 54 (2-3), 267-282 (16 pages). 
Doll, T.; Frimmel, F., (2004). Kinetic study of photocatalytic degradation of carbamazepine, clofibric acid, iomeprol and iopromide assisted by different $\mathrm{TiO}_{2}$ materialsdetermination of intermediates and reaction pathways. Water Res., 38 (4), 955-964 (10 pages).

Doll, T.; Frimmel, F., (2005a). Cross-flow microfiltration with periodical back-washing for photocatalytic degradation of pharmaceutical and diagnostic residues-evaluation of the long-term stability of the photocatalytic activity of $\mathrm{TiO}_{2}$. Water Res., 39 (5), 847-854 (8 pages)

Doll, T.; Frimmel, F., (2005b). Photocatalytic degradation of carbamazepine, clofibric acid and iomeprol with P25 and Hombikat UV100 in the presence of natural organic matter (NOM) and other organic water constituents. Water Res., 39 (2-3), 403-411 (9 pages).

Doll, T.; Frimmel, F., (2005c). Removal of selected persistent organic pollutants by heterogeneous photocatalysis in water. Catal. Today, 101 (3-4), 195-202 (8 pages).

Dutta, M.; Baruah, R.; Dutta, N., (1997). Adsorption of 6aminopenicillanic acid on activated carbon, Sep. Purif. Tech., 12 (2), 99-108 (10 pages).

Dutta, P.; Ray, A., (2004). Experimental investigation of Taylor vortex photocatalytic reactor for water purification. Chem. Eng. Sci., 59 (22-23), 5249-5259 (11 pages).

El Gohary, F.; Abou-Elea, S., (1995). Evaluation of biological technologies for wastewater treatment in the pharmaceutical industry. Water Sci. Tech., 32(11), 13-20 (8 pages).

Enick, O.; Moore, M., (2007). Assessing the assessments: Pharmaceuticals in the environment. Environ. Impact. Asses., 27 (8), 707-729 (23 pages).

Enright, A.; McHugh, S.; Collins, G.; O’Flaherty, V., (2005). Low-temperature anaerobic biological treatment of solvent containing pharmaceutical wastewater. Water Res., 39 (19), 4587-4596 (10 pages).

Feng, X.; Ding, J.; Wu F.; Deng, N., (2005). Degradation of estrone in aqueous solution by photo-Fenton system. Sci. Total Environ., 345 (1-3), 229-237 (9 pages).

Flores, A.; Hill, E., (2008). Formation of estrogenic brominated ethinylestradiol in drinking water: implications for aquatic toxicity testing. Chemosphere, 73 (7), 1115-1120 (6 pages).

Fountoulakis, M.; Stamatelatou, K.; Lyberatos, G., (2008). The effect of pharmaceuticals on the kinetics of methanogenesis and acetogenesis. Bioresour. Tech., 99 (15), 7083-7090 (8 pages).

Gangagni Rao, A.; Venkata Naidu, G.; Krishna Prasad, K.; Chandrasekhar Rao, N.; Venkata Mohan, S.; Jetty, A.; Sarma P., (2005). Anaerobic treatment of wastewater with high suspended solids from a bulk drug industry using fixed film reactor (AFFR). Bioresour. Tech., 96(1), 87-93 (7 pages).

Gaya, U.; Abdullah, A., (2008). Heterogeneous photocatalytic degradation of organic contaminants over titanium dioxide: A review of fundamentals, progress and problems. J. Photoch. Photobio. C., 9 (1), 1-12 (12 pages).

Gharbani, P.; Khosravi, M.; Tabatabaei, S. M.; Zare, K.; Dastmalchi, S.; Mehrizad, A., (2010). Degradation of trace aqueous 4-chloro-2-nitrophenol occurring in pharmaceutical industrial wastewater by ozone. Int. J. Environ. Sci. Tech., 7 (2), 377-384 (8 pages).

Giri, R. R.; Ozaki, H.; Taniguchi, S.; Takanami, R., (2008) Photocatalytic Ozonation of 2, 4-dichlorophenoxyacetic acid in water with a new $\mathrm{TiO}_{2}$ fiber, Int. J. Environ. Sci. Tech., 5 (1), 17-26 (10 pages).

Giri, R. R.; Ozaki, H.; Ota, S.; Takanami, R.; Taniguchi, S., (2010), Degradation of common pharmaceuticals and personal care products in mixed solutions by advanced oxidation techniques, Int. J. Environ. Sci. Tech., 7 (2), 251 260 (10 pages)

Giri R. R.; Ozaki, H.; Takayanagi, Y.; Taniguchi S.; Takanami R., (2011) Efficacy of ultraviolet radiation and hydrogen peroxide oxidation to eliminate large number of pharmaceutical compounds in mixed solution, Int. J. Environ. Sci. Tech., 8 (1), 19-30 (12 pages)

Hartig, C.; Ernst, M.; Jekel, M., (2001). Membrane filtration of two sulphonamides in tertiary effluents and subsequent adsorption on activated carbon. Water Res., 35 (16), 39984003 (6 pages)

Heberer, T., (2002). Occurrence, fate, and removal of pharmaceutical residues in the aquatic environment: a review of recent research data. Toxicol. Lett., 131 (1-2), 5-17 (13 pages).

Helmig, E.; Fettig, J.; Cordone, L., (2007). API Removal from Pharmaceutical Manufacturing Wastewater - Results of Process Development, Pilot-Testing, and Scale-Up WEF Session, Rhode Island.

Herrmann, J., (1999). Heterogeneous photocatalysis: fundamentals and applications to the removal of various types of aqueous pollutants. Catal. Today, 53 (1), 115-129 (15 pages).

Herrmann, J., (2005). Heterogeneous photoatalysis: state of the art and present applications. Top. Catal., 34 (1-4), 4965 (17 pages).

Hrubec, J.; Vankreijl, C.; Orra, C., (1983). Treatment of Municipal Wastewater by Reverse-Osmosis and ActivatedCarbon-Removal of Organic Micropollutants and Reduction of Toxicity. Sci. Total Environ., 27 (1), 71-88 (18 pages).

Huber, M.; Canonica, S.; Park, G.; von Gunten, U., (2003). Oxidation of Pharmaceuticals during Ozonation and Advanced Oxidation Processes, Environ. Sci. Tech., 37 (5) 1016-1024 (9 pages).

Huber, M.; Gobel, A.; Joss, A.; Hermann, N.; Loffler, D.; McArdell, C.; Ried, A.; Siegrist, A.; Ternes, T.; von Gunten, U., (2005). Oxidation of pharmaceuticals during ozonation of municipal wastewater effluents: a pilot study, Environ. Sci. Tech., 39 (11), 4290-4299 (10 pages).

Ikehata, K.; Naghashkar, N.; El-Din, M., (2006). Degradation of Aqueous Pharmaceuticals by Ozonation and Advanced Oxidation Processes: A Review. Ozone-Sci. Eng., 28 (6), 353-414 (62 pages).

Ileri, R.; Sengil, I.; Kulac, S.; Damar, Y.; (2003). Treatment of mixed pharmaceutical industry and domestic wastewater by sequencing batch reactor. J. Environ. Sci Heal. A., 38 (10), 2101-2111 (11 pages)

Jones, O.; Voulvoulis, N.; Lester, J., (2007). The occurrence and removal of selected pharmaceutical compounds in a sewage treatment works utilising activated sludge treatment. Environ. Pollut., 145 (3), 738-744 (7 pages).

Joss, A.; Keller, E.; Alder, A.; Göbel, A.; McArdell, C.; Ternes, T.; Siegrist, H., (2005). Removal of pharmaceuticals and fragrances in biological wastewater treatment. Water Res., 39 (14), 3139-3152 (14 pages).

Kavitha, V.; Palanivelu, K., (2004). The role of ferrous ion in 
Fenton and photo- Fenton processes for the degradation of phenol. Chemosphere, 55 (9), 1235-1243 (9 pages).

Keane, D.; Basha, S.; Nolan, K,; Morrissey, A.; Tobin, J., (2011) Photodegradation of famotodine by integrated photocatalytic adsorbent (IPCA) and kinetic study. Catal. Lett., 141 (2), 300-308 (10 pages).

Khetan, S.; Collins, T., (2007). Human Pharmaceuticals in the Aquatic Environment: A Challenge to Green Chemistry. Chem. Rev., 107 (6), 2319-2364 (46 pages).

Kimura, K.; Amy, G.; Drewes, J.; Heberer, T.; Kim, T.; Watanabe, Y., (2003). Rejection of organic micropollutants (disinfection by-products, endocrine disrupting compounds, and pharmaceutically active compounds) by NF/RO membranes. J. Membr. Sci., 227 (1-2), 113-121 (9 pages).

Kolpin, D.; Furlong, E.; Meyer, M.; Thurman, E.; Zaugg, S.; Barber, L.; Buxton, H., (2002). Pharmaceuticals, hormones, and other organic wastewater contaminants in U.S. streams, 1999-2000: a national reconnaissance. Environ. Sci. Tech., 36 (6), 1202-1211 (9 pages).

Kulik, N.; Trapido, M.; Goi, A.; Veressinina, Y.; Munter, R., (2008). Combined chemical treatment of pharmaceutical effluents from medical ointment production. Chemosphere, 70 (8), 1525-1531 (7 pages).

LaPara, T.; Nakatsu, C.; Pantea, L.; Alleman, J., (2001a). Aerobic biological treatment of a pharmaceutical wastewater: Effect of temperature on cod removal and bacterial community development. Water Res., 35 (18), 4417-4425 (9 pages).

LaPara, T.; Konopka, A.; Nakatsu, C.; Alleman, J., (2001b). Thermophilic aerobic treatment of a synthetic wastewater in a membrane-coupled bioreactor. J. Ind. Microbiol. Biotech., 26 (4), 203-209 (7 pages).

LaPara, T.; Nakatsu, C.; Pantea, L.; Alleman, J., (2002). Stability of the bacterial communities supported by a seven-stage biological process treating pharmaceutical wastewater as revealed by PCR-DGGE. Water Res., 36 (3), 638-646 (9 pages).

Larsen, T.; Lienert, J.; Joss, A.; Siegrist, H., (2004). How to avoid pharmaceuticals in the aquatic environment. J. Biotech., 113 (1-3), 295-304 (10 pages).

Larsson, D.; Adolfsson-Erici, M.; Parkkonen, J.; Pettersson, M.; Berg, A.; Olsson, P.; Förlin, L., (1999). Ethinyloestradiol - an undesired fish contraceptive. Aquat. Toxicol., 45 (2-3), 91-97 (7 pages).

Larsson, D.G.J., Fick, J., (2009), Transparency throughout the production chain-a way to reduce pollution from the manufacturing of pharmaceuticals. Regul. Toxicol. Pharm., 53 (3), 161-163 (3 pages).

Lee, J.; Nam, W.; Kang, M.; Han, G.; Yoon, K.; Kim, M.; Ogion, K.; Miyata, S.; Choung, S., (2003). Design of two types of fluidised photoreactors and their photo-catalytic performances for degradation of methyl orange. Appl. Catal. A-Gen., 244 (1), 49-57 (9 pages).

Lee, Y.; von Gunten, U., (2009). Kinetics of the oxidation of phenols and phenolic of 17 â-estradiol and their estrogenic activities, Environ. Sci. Tech., 43 (22), 480-487 (8 pages).

Legrini, O.; Oliveros, E.; Braun, A., (1993), Photochemical Processes for Water-Treatment. Chem. Rev., 93 (2), 671 698 (28 pages).

Lhomme, L.; Brosillon, S.; Wolbert, D., (2008). Photocatalytic degradation of pesticides in pure water and a commercial agricultural solution on $\mathrm{TiO}_{2}$ coated media. Chemosphere, 70 (3), 381-386 (6 pages)

Li, Y.; Li, X.; Li, J.; Yin, J., (2005). Photocatalytic degradation of methyl orange in a sparged tube reactor with $\mathrm{TiO}^{2}$-coated activated carbon composites. Catal. Commun., 6 (10), 650655 (6 pages)

Lillenberg, M.; Yurchenko, S.; Kipper, K.; Herodes, K.; Pihl, V.; Lõhmus, R.; Ivask, M.; Kuu, A.; Kutti, S.; Litvin, S. V.; Nei, L., (2010). Presence of fluoroquinolones and sulfonamides in urban sewage sludge and their degradation as a result of composting. Int. J. Environ. Sci. Tech., 7 (2), 307-312 (6 pages).

Madukasi, E. I.; Dai, X.; He, C.; Zhou, J., (2010). Potentials of phototrophic bacteria in treating pharmaceutical wastewater. Int. J. Environ. Sci. Tech., 7 (1), 165-174 (11 pages).

Malato, S.; Blanco, J.; Vidal, A.; Fernandez, P.; Caceres, J.; Trincado, P., (2002). New large solar photocatalytic plant: set-up and preliminary results. Chemosphere, 47 (3), 235240 (6 pages).

Malato, S.; Blanco, J.; Alarcon, D.; Maldonado, M.; FernandezIbanez, P.; Gernjak, W., (2007). Photocatalytic decontamination and disinfection of water with solar collectors. Catal. Today, 122 (1-2), 137-149 (13 pages).

Mandelbaum, P.; Regazzoni, A.; Blesa, M.; Bilmes S., (1999). Photo-electro-oxidation of alcohols on titanium dioxide thin film electrodes. J. Phys. Chem. B., 103 (26), 5505-5511.

Miège, C.; Choubert, J.; Ribeiro, L.; Eusèbe, M.; Coquery, M., (2008). Removal efficiency of pharmaceuticals and personal care products with varying wastewater treatment processes and operating conditions - conception of a database and first results, Water Sci. Tech., 57 (1), 49-56 (7 pages).

Miege, C.; Choubert, J.; Ribeiro, L.; Eusebe, M.; Coquery, M., (2009). Fate of pharmaceuticals and personal care products in wastewater treatment plants - Conception of a database and first results, Environ. Pollut., 157 (5), 1721-1726 (6 pages).

Mozia, S.; Tomaszewska, M.; Morawski, A., (2005). Decomposition of nonionic surfactant in a labyrinth flow photoreactor with immobilised $\mathrm{TiO}_{2}$ bed. Appl. Catal. BEnviron., 59 (3-4), 155-160 (6 pages)

Munoz, I.; Peral, J.; Ayllon, J.; Malato, S.; Passarinho, P.; Domenech, X., (2006). Life cycle assessment of a coupled solar photocatalytic-biological process for wastewater treatment. Water Res., 40 (19), 3533-3540 (8 pages).

Nagaoka, S.; Hamasaki, Y.; Ishihara, S.; Nagata, M.; Iio, K.; Nagasawa, C., (2002). Preparation of carbon/ $\mathrm{TiO}_{2}$ microsphere composites from cellulose/ $\mathrm{TiO}$ microsphere composites and their evaluation. J. Mol. Catal. A: Chem., 177 (2), 255-263 (9 pages).

Nakada, H.; Shinohara, A.; Murata, K.; Kiri, S.; Managaki, N.; Sato, N.; Takada, H., (2007). Removal of selected pharmaceuticals and personal care products (PPCPs) and endocrine-disrupting chemicals (EDCs) during sand filtration and ozonation at a municipal sewage treatment plant, Water Res., 41 (19), 4372-4382 (11 pages).

Nghiem, L.; Schafer, A.; Elimelech, M., (2005). Pharmaceutical retention mechanisms by nanofiltration membranes. Environ. Sci. Tech., 39 (19), 7698-7705 (8 pages).

Noble, J., (2006), GE ZeeWeed MBR technology for pharmaceutical wastewater treatment. Membrane Tech., 2006 (9), 7-9 (3 pages).

Oaks, J.; Gilbert, M.; Virani, M.; Watson, R.; Meteyer, C.; Rideout, B.; Shivaprasad, H.; Ahmed, S.; Iqbal Chaudhry, M.; Arshad, M.; Mahmood, S.; Ali, A.; Khan, A., (2004). Diclofenac residues as the cause of vulture population decline in Pakistan. Nature, 427 (6975), 630-633 (4 pages).

Oktem, Y.; Ince, O.; Sallis, P.; Donnelly, T.; Ince, B., (2007). Anaerobic treatment of a chemical synthesis-based 
pharmaceutical wastewater in a hybrid upflow anaerobic sludge blanket reactor. Bioresour. Tech., 99 (5), 1089-1096 (8 pages).

Oller, I.; Malato, S.; Sánchez-Pérez, J.; Maldonado, M.; Gernjak, W.; Pérez-Estrada, L.; Muñoz, J.; Ramos, C.; Pulgarín, C., (2007). Pre-industrial-scale Combined Solar Photo-Fenton and Immobilised Biomass Activated-Sludge Biotreatment. Ind. Eng. Chem., 46 (23), 7467-7475 (9 pages).

Ollis, D., (2003). Integrating Photocatalysis and Membrane Technologies for Water Treatment, Ann. N. Y. Acad. Sci., 984 (1), 65-84 (20 pages).

Oz, N.; Ince, O.; Ince, B., (2004). Effect of wastewater composition on methanogenic activity in an anaerobic reactor. J. Environ. Sci. Heal. A., 39 (11-12), 2029-2042 (14 pages).

Ozaki, H.; Li, H., (2002). Rejection of organic compounds by ultralow pressure reverse osmosis membrane. Water Res., 36 (1), 123-130 (8 pages).

Perez-Estrada, L.; Malato, S.; Gernjak, W.; Aguera, A.; Thurman, E.; Ferrer, I.; Fernandez-Alba, A., (2005a). Photo-Fenton Degradation of Diclofenac: Identification of Main Intermediates and Degradation Pathway. Environ. Sci. Tech., 39 (21), 8300-8306 (7 pages).

Pérez-Estrada, L.; Maldonado, M.; Gernjak, W.; Agüera, A.; Fernández-Alba, A.; Ballesteros, M.; Malato, S., (2005b). Decomposition of diclofenac by solar driven photocatalysis at pilot plant scale. Catal. Today, 101 (3-4), 219-226 (8 pages).

Pinkston, K.; Sedlak, D., (2004). Transformation of Aromatic Ether and Amine Containing Pharmaceuticals during Chlorine Disinfection. Environ. Sci. Tech., 38 (14), 4019-4025 (7 pages).

Puma, L.; Yue, P., (2001). The modelling of a fountain photocatalytic reactor with a parabolic profile. Chem. Eng. Sci., 56 (2), 721-726 (6 pages).

Qiang, Z.; Macauley, J.; Mormile, M.; Surampalli, R.; Adams, C., (2006). Treatment of Antibiotics and Antibiotic Resistant Bacteria in Swine Wastewater with Free Chlorine. J. Agr. Food Chem., 54 (21), 8144-8154 (11 pages).

Radjenovic, J.; Petrovic, M.; Barcelo, D., (2007). Analysis of pharmaceuticals in wastewater and removal using a membrane bioreactor. Anal. Bioanal. Chem., 387 (4), 1365-1377 (13 pages).

Rao, N.; Dubey, A.; Mohanty, S.; Khare, P.; Jain, R.; Kaul, S., (2003). Photocatalytic degradation of 2-chlorophenol: a study of kinetics, intermediates and biodegradability. J. Hazard. Mater., B., 101 (3), 301-314 (14 pages).

Ravina, M.; Campanella, L.; Kiwi, J., (2002). Accelerated mineralisation of the drug Diclofenac via Fenton reactions in a concentric photo-reactor. Water Res., 36 (14), 3553-3560 (8 pages).

Ray, A., (1998). A new photocatalytic reactor for destruction of toxic water pollutants by advanced oxidation process. Catal. Today, 44 (1-4), 357-368 (12 pages).

Rios-Enriquez, M.; Shahin, N., (2004). Optimisation of the heterogeneous Fenton-oxidation of the model pollutant 2,4xylidine using the optimal experimental design methodology. Sol. Energy, 77 (5), 491-501 (11 pages).

Rosenfeldt, E.; Linden K., (2004). Degradation of endocrine disrupting chemicals bisphenol A, ethinyl estradiol, and estradiol during UV photolysis and advanced oxidation processes. Environ. Sci. Tech., 38 (20), 5476-5483 (8 pages).

Rudder, J.; Wiele, T.; Dhooge, W.; Comhaire, F.; Verstraete, W.,
(2004). Advanced water treatment with manganese oxide for the removal of 17 [alpha]-ethynylestradiol (EE2). Water Res., 38 (1), 184-192 (9 pages).

Serpone, N.; Pelizzetti, E., (1989). Photocatalysis: Fundamentals and Applications. Wiley, New York.

Shemer, H.; Kunukcu, Y.; Linden, K., (2006). Degradation of the pharmaceutical metronidazole via UV, Fenton and photoFenton processes. Chemosphere, 63 (2), 269-276 (8 pages).

Snyder, S.; Adham, S.; Redding, A.; Cannon, F.; DeCarolis, J.; Oppenheimer, J.; Wert, E.; Yoon, Y., (2007). Role of membranes and activated carbon in the removal of endocrine disruptors and pharmaceuticals. Desalination, 202 (1-3), 156181 (26 pages).

Sreekanth, D.; Sivaramakrishna, D.; Himabindu, V.; Anjaneyulu, Y., (2009). Thermophilic treatment of bulk drug pharmaceutical industrial wastewaters by using hybrid up flow anaerobic sludge blanket reactor. Bioresour. Tech., 100 (9), 2534-2539 (6 pages).

Stamatelatou, K.; Vavilin, V.; Lyberatos, G., (2003). Performance of a glucose fed periodic anaerobic baffled reactor under increasing organic loading conditions: 1. Experimental results. Bioresour. Tech., 88 (2), 131-136 (6 pages).

Stapleton, D.; Emery, R.; Mantzavinos, D.; Papadaki, M., (2006). Photolytic Destruction of Halogenated Pyridines in Wastewaters. Process Saf. Environ., 84 (4), 313-316 (4 pages)

Stumm-Zollinger, E.; Fair, G. M., (1965). Biodegradation of steroid hormones. Res. J. Water Pollut. C., 37 (11), 15061510 (5 pages).

Suarez, S.; Lema, J.; Omil, F., (2009). Pre-treatment of hospital wastewater by coagulation-flocculation and flotation. Bioresour. Tech., 100 (7), 2138-2146 (9 pages).

Suman Raj, D.; Anjaneyulu, Y., (2005). Evaluation of biokinetic parameters for pharmaceutical wastewaters using aerobic oxidation integrated with chemical treatment. Process Biochem., 40 (1), 165-175 (11 pages).

Suri, R.; Nayak, M.; Devaiah, U.; Helmig, E., (2007). Ultrasound assisted destruction of estrogen hormones in aqueous solution: Effect of power density, power intensity and reactor configuration. Microb. Cell Fact., 146 (3), 472-478 (7 pages).

Takashi, T.; Shi-Cong Cui, S.; Mamoru, F.; Tetsuro, M., (2007). Nanoscopic heterogeneities in adsorption and electron transfer processes of perylene diimide dye on $\mathrm{TiO}_{2}$ nanoparticles studied by single-molecule fluorescence spectroscopy. Chem. Phys. Lett., 443 (4-6), 313-318 (6 pages).

Ternes, T. A.; Meisenheimer, M.; McDowell, D.; Sacher, F.; Brauch, H.; Haist-Gulde, B.; Preuss, G.; Wilme, U.; Zulei-Seibert, N., (2002). Removal of pharmaceuticals during drinking water treatment. Environ. Sci. Tech., 36 (17), 3855- 3863 (9 pages).

Ternes, T.; Stüber, J.; Herrmann, N.; McDowell, D.; Ried, A.; Kampmann, M.; Teiser, B., (2003). Ozonation: a tool for removal of pharmaceuticals, contrast media and musk fragrances from wastewater. Water Res., 37(8), 1976-1982 (7 pages).

Ternes, T.; Herrmann, N.; Bonerz, M.; Knacker, T.; Siegrist, H.; Joss, A., (2004). Rapid method to measure the solidwater distribution coefficient $\left(\mathrm{K}_{d}\right)$ for pharmaceuticals and musk fragrances in sewage sludge. Water Res., 38 (19), 40754084 (10 pages).

Trovo, A.; Melo, S.; Nogueira, R., (2008). Photodegradation of the pharmaceuticals amoxicillin, bezafibrate and paracetamol 
by the photo-Fenton process-Application to sewage treatment plant effluent. J. Photoch. Photobio. A, 198 (23), 215-220 (6 pages).

Tungudomwongsa, H.; Leckie, J.; Mill, T., (2006). Photocatalytic oxidation of emerging contaminants: kinetics and pathways for photocatalytic oxidation of pharmaceutical compounds. J. Adv. Oxidation Tech., 9 (1), 59-64 (6 pages).

Urase, T.; Kagawa, C.; Kikuta, T., (2005). Factors affecting removal of pharmaceutical substances and estrogens in membrane separation bioreactors. Desalination, 178 (1-3), 107-113 (7 pages).

Vogna, D.; Marotta, R.; Napolitano, A.; d'Ischia, M., (2002). Advanced oxidation chemistry of paracetamol. $\mathrm{UV} / \mathrm{H}_{2} \mathrm{O}_{2}$ induced hydroxylation/degradation pathways and (15) $\mathrm{N}$-aided inventory of nitrogenous breakdown products. J. Org. Chem., 67 (17), 6143-6151 (9 pages).

Vogna, D.; Marotta, R.; Napolitano, A.; Andreozzi, R.; d'Ischia, M., (2004a). Advanced oxidation of the pharmaceutical drug diclofenac with $\mathrm{UV} / \mathrm{H}_{2} \mathrm{O}_{2}$ and ozone. Water Res., 38 (2), 414422 (9 pages).

Vogna, D.; Marotta, R.; Andreozzi, R.; Napolitano, A.; d'Ischia, M., (2004b). Kinetic and chemical assessment of the UV/ $\mathrm{H}_{2} \mathrm{O}_{2}$ treatment of antiepileptic drug carbamazepine. Chemosphere, 54 (4), 497-505 (9 pages).

Watkinson, A.; Murby, E.; Costanzo, S., (2007). Removal of antibiotics in conventional and advanced wastewater treatment: Implications for environmental discharge and wastewater recycling. Water Res., 41 (18), 4164-4176 (13 pages)

Webb, S.; Ternes, T.; Gibert, M.; Olejniczak, K., (2003). Indirect human exposure to pharmaceuticals via drinking water. Toxicol. Lett., 142 (3), 157-167 (11 pages).

Wei, T.; Wan, C., (1992) Kinetics of photocatalytic oxidation of phenol on $\mathrm{TiO}_{2}$ surface. J. Photochem. Photobiol. A6 Chem., 69 (2), 241-249 (9 pages).

Werner, J.; McNeill, K.; Arnold, W., (2005). Environmental Photodegradation of Mefenamic Acid. Chemosphere, 58 (10), 1339-1346 (8 pages).

Westerhoff, P.; Yoon, Y.; Snyder, S.; Wert, E., (2005). Endocrine disruptor, pharmaceutical, and personal care product fate during simulated drinking water treatment processes. Environ. Sci. Tech., 39 (17), 6649-6663 (15 pages).

$\mathrm{Xu}$, Y.; Langford, C., (2001). UV- or visible-light-Induced degradation of $\mathrm{X} 3 \mathrm{~B}$ on $\mathrm{TiO}_{2}$ nanoparticles: the influence of adsorption. Langmuir, 17 (3), 897-902 (6 pages).

Xu, K.; Harper, W.; Zhao, D., (2008). 17â-ethinylestradiol sorption to activated sludge biomass: Thermodynamic properties and reaction mechanisms. Water Res., 42 (12), 3146- 3152 (7 pages).

Xu, P.; Drewes, J.; Bellona, C.; Amy, G.; Kim, T.; Adam, M.; Heberer, T., (2005). Rejection of emerging organic micropollutants in nanofiltration-reverse osmosis membrane applications. Water Environ. Res., 77 (1), 40-48 (9 pages).

Yang, W.; Cicek, N.; Ilg, J., (2006). State-of-the-art of membrane bioreactors: Worldwide research and commercial applications in North America, J. Membrane Sci., 270 (1-2), 201-211 (11 pages).

Yatmaz, H.; Wallis, G.; Howarth, C., (2005). The spinning disc reactor-studies on a novel $\mathrm{TiO}_{2}$ photocatalytic reactor. Chemosphere, 42 (4), 397-403 (7 pages).

Yoon, Y.; Westerhoff, P.; Snyder, S., (2005). Adsorption of ${ }^{3} \mathrm{H}-$ labeled 17-â-estradiol on powdered activated carbon. Water, Air, Soil Pollut., 166 (1-4), 343-351 (9 pages).

Yoon, Y.; Westerhoff, P.; Snyder, S.; Wert, E., (2006). Nanofiltration and ultrafiltration of endocrine disrupting compounds, pharmaceuticals and personal care products. J. Membr. Sci., 270 (1-2), 88-100 (13 pages).

Yuan, F.; Hu, C.; Hu, X.; Qu, J.; Yang, M., (2009). Degradation of selected pharmaceuticals in aqueous solution with UV and $\mathrm{UV} / \mathrm{H}_{2} \mathrm{O}_{2}$. Water Res., 43 (6), 1766-1774 (6 pages).

Zhang, Z.; Anderson, W.; Moo-Young, M., (2004). Experimental analysis of a corrugated plate photocatalytic reactor. Chem. Eng., 99 (2), 145-152 (8 pages).

Zhang, Y.; Zhou, J., (2005). Removal of estrone and 17âestradiol from water by adsorption. Water Res., 39 (16), 3991-4003 (13 pages).

Zwiener, C.; Frimmel, F., (2003). Short-term tests with a pilot sewage plant and biofilm reactors for the biological degradation of the pharmaceutical compounds clofibric acid, ibuprofen, and diclofenac. Sci. Total Environ., 309 (1-3), 201-211 (11 pages).

\section{AUTHOR (S) BIOSKETCHES}

Deegan, A. M., Ph.D. candidate, School of Biotechnology, Dublin City University, Dublin 9, Ireland. Email: deegana2@gmail.com

Shaik, B., Research fellow, School of Biotechnology, Dublin City University, Dublin 9, Ireland. Email: Bhasha.Shaik@dcu.ie

Nolan, K., Lecturer, School of Chemical Sciences, Dublin City University, Dublin 9, Ireland. Email: Kieran.nolan@dcu.ie

Urell, K., Visiting student, School of Biotechnology, Dublin City University, Dublin 9, Ireland. Email: kate.urell@oceanfree.net

Oelgemöller M., Ph.D., Professor, School of Pharmacy and Molecular Sciences, James Cook University, Townsville, 4811, Australia Email: michael.oelgemoeller@jcu.edu.au

Tobin, J., Senior Lecturer, School of Biotechnology, Dublin City University, Dublin 9, Ireland. Email: john.tobin@dcu.ie

Morrissey, A., Ph.D., Lecturer, Oscail, Dublin City University, Dublin 9 Ireland. Email: anne.morrissey@dcu.ie 